\title{
Da palavra à construção de conhecimento científico: um olhar reflexivo e meta-avaliativo sobre o guião de entrevista
}

\author{
From words to the scientific knowledge: a reflexive and meta-evaluative \\ look at the interview guide
}

\section{De la palabra a la construcción del conocimiento científico: una mirada reflexiva y meta-evaluativa sobre el guión de entrevistas}

\author{
Maria José Silvestre ${ }^{1}$ \\ Isabel Fialho ${ }^{2}$ \\ José Saragoça ${ }^{3}$ \\ http://dx.doi.org/10.5216/31793
}

\begin{abstract}
Resumo
Este estudo insere-se no âmbito do projeto de investigação «Impacto e Efeitos da Avaliação Externa nas Escolas do Ensino não Superior»-AEEENS e procura contribuir para o alargamento do conhecimento científico na área das metodologias qualitativas, nomeadamente ao nível da meta-análise. Procurando realizar um olhar reflexivo e meta-avaliativo sobre o guião de entrevista, a análise de conteúdo e análise do discurso (que o inquérito por entrevista potencia), partimos da seguinte questão: «Quais são os procedimentos desejados / desejáveis para a utilização da técnica de recolha de dados "inquérito por entrevista" numa investigação científica?». O objetivo primordial é a produção e apresentação de um instrumento metaavaliativo, sob a forma de 'lista de verificação' ou checklist avaliativa, destinado a ser usado como ferramenta de apoio na construção e na validação de guiões de entrevista e que integra catorze indicadores. As principais conclusões evidenciam que essa validação consiste num ato de atribuição de 'qualidade' a esse instrumento investigativo. A meta-avaliação de um guião de entrevista semiestruturada pode revelar-se de extrema pertinência e validade, uma vez que da validação do guião dependerá, em última instância, o resultado mais ou menos conseguido da tarefa investigativa. $\mathrm{O}$ estudo revelou ainda a necessidade de os investigadores envolvidos neste tipo de processos perfilharem o mesmo ponto de vista, uma vez que, tratando-se de uma análise de dados qualitativa, a análise de conteúdo dever estar em permanente revisão, processando-se de forma cíclica e circular, necessitando do olhar e da atenção do investigador para dos dados extrair significados.
\end{abstract}

Palavras-chave: Meta-avaliação. Meta-análise. Entrevista semiestruturada. Análise de conteúdo. Análise do discurso.

\begin{abstract}
The study integrates the research project "Impact and Effects of External Evaluation in Schools of Higher Education not»- AEEENS and it seeks to contribute to the expansion of scientific knowledge in the area of qualitative methodologies, particularly in terms of meta-analysis. We propose to offer a reflective look and meta-evaluation on the interview guide, content analysis and discourse analysis (that the interview increases). We start with the following question:

1 Doutora em Ciências da Educação na Universidade de Évora. Portugal, Évora. E-mail: mariajosesg.silvestre@gmail.com

${ }^{2}$ Doutora em Ciências da Educação na Universidade de Évora. Portugal, Évora. E-mail: ifialho@evora.pt

${ }^{3}$ Doutor em Sociologia na Universidade de Évora. Investigador do CESNova/FCSH-UNL. Portugal, Évora. E-mail: jsaragoca@evora.pt
\end{abstract}

Comun. \& Inf., Goiânia, GO, v. 17, n. 2, p. 119-138, jul./dez. 2014. 
'What are the desired / desirable procedures for the use of the technique of data collection "Interview Survey" in scientific research?', having as main objective the production and presentation of a meta-evaluation method in the form of evaluative checklist, designed to be used as a support tool in the construction and validation of interview guides. Thus, we present an evaluation checklist that includes fourteen indicators to allow the assignment of more or less quality to the interview guide analysed. The main findings show that this validation is an act of allocating 'quality' in this investigative tool. A meta-evaluation of a semi-structured interview script may demonstrate its extreme relevance and validity, since the more or less successfully result of the investigative task will depend on the validation of the interview guide. The study also revealed the need for researchers involved in these processes share the same point of view, since, in the case of an analysis of qualitative data, content analysis should be kept under review, continuously and circularly, requiring the look and the attention of the investigator to extract meaning from data.

Keywords: Meta-review. Meta-analysis. Stuctured interviews. Contente analysis. Discourse analysis.

\section{Resumen:}

Este estudio forma parte del proyecto de investigación titulado "Impacto y Efectos de la Evaluación Externa en las Escuelas de Enseñanza No Superior" - AEEENS y busca contribuir a la expansión del conocimiento científico en el área de las metodologías cualitativas, particularmente en el ámbito del meta-análisis. Para realizar una mirada reflexiva y metaevaluativa sobre la guía de entrevistas, el análisis de contenido y el análisis del discurso (que es favorecido por la entrevista), comenzamos haciéndonosla siguiente pregunta: ¿Cuáles son los procedimientos deseados/deseables para la utilización de la técnica de recogida de datos de "Encuestas por entrevistas" en la investigación científica?". El objetivo principal es la producción y presentación de un instrumento meta-evaluativo, en forma de lista de verificación, destinado a ser usado como herramienta de apoyo en la construcción y validación de guiones de entrevista y que incluye catorce indicadores que permiten asignar una mayor o menor calidad de la guía de entrevista analizada. Las principales conclusiones evidencian que esa validación es un acto de asignación de la "calidad" de esta herramienta de investigación. Una meta-evaluación de un guión de entrevista semiestructurada puede demostrar su extrema relevancia y validez, ya que el resultado más o menos exitoso de la tarea de investigación dependerá, en última instancia, de la validación del guión de entrevista. El estudio también reveló la necesidad de que los investigadores involucrados en estos procesos compartan el mismo punto de vista, ya que, en el caso de un análisis de datos cualitativos, el análisis de contenido debe ser revisado permanentemente, procesándose de forma cíclica y circular, necesitando de una mirada y una atención del investigador para extraer el significado de los datos.

Palabras clave: Meta-evaluación. Meta-análisis. Entrevista Semiestructurada. Análisis del contenido. Análisis del discurso.

\section{INTRODUCÃO}

Este trabalho insere-se no projeto de investigação Impacto e Efeitos da Avaliação Externa nas Escolas do Ensino não Superior (AEEENS ${ }^{4}$ ). O estudo funda-se na intencionalidade de contribuir para o alargamento do conhecimento científico na área

\footnotetext{
4 Projeto PTDC/CPE-CED/116674/2010, financiado por Fundos FEDER através do Programa Operacional Fatores de Competitividade - COMPETE e por Fundos Nacionais através da FCT Fundação para a Ciência e a Tecnologia de Portugal.
}

Comun. \& Inf., Goiânia, GO, v. 17, n. 2, p. 119-138, jul./dez. 2014. 
das metodologias qualitativas, nomeadamente ao nível da meta-análise, propondo um olhar reflexivo e meta-avaliativo sobre análise de conteúdo e análise do discurso (que o inquérito por entrevista potencia), partilhando com a comunidade académica em geral o resultado, ainda que parcial, de uma investigação científica na área das Ciências da Educação.

O caráter transversal e multidisciplinar da abordagem qualitativa em investigação (Costa, Souza \& Souza, 2014) coloca-nos, simultaneamente, dois desafios: a mais-valia de um olhar reflexivo que beneficia do contributo de várias disciplinas (tais como a Hermenêutica, a Linguística e, em especial, a Teoria do Texto, a Sociologia ou mesmo a Psicologia, entre outras) e a possibilidade de aplicação de um instrumento metodológico como o que neste texto apresentamos (uma Checklist Avaliativa de um Guião de Entrevista) a variadas áreas do conhecimento e da atuação académica investigativa.

Assim, embora conscientes dos desafios que a investigação qualitativa coloca ao investigador (tais como o papel do investigador e a sua relação quer com o(s) participante(s), quer com o objeto de estudo, a seleção/produção dos instrumentos e sua validação ou as questões da subjetividade e da fiabilidade da interpretação), estamos em crer que este paper poderá constituir-se enquanto texto-âncora para os investigadores iniciantes (que nele encontrarão sistematizados os procedimentos e etapas metodológicos que entendemos deverem ser tidos em conta aquando da realização de entrevistas semiestruturadas), bem como para investigadores com a responsabilidade de orientação de dissertações ou teses, que nele poderão encontrar um instrumento metaavaliativo capaz de suportar e validar a análise da qualidade de guiões de entrevista propostos para validação.

Partilhamos com Elliot (2011) a definição de meta-avaliação como uma avaliação da avaliação para, mais especificamente, nos posicionarmos no objetivo central deste estudo. Assim, pretende-se averiguar a 'qualidade' da análise levada a cabo, ou seja, proceder a uma análise da análise de conteúdo efetuada. Numa palavra, proceder a uma meta-análise.

\section{QUESTÕES E OBJETIVOS DO ESTUDO}

Partimos da definição do tema central enunciado no subtítulo para, de seguida, estabelecermos como finalidade a produção de conhecimento científico sobre a validade

Comun. \& Inf., Goiânia, GO, v. 17, n. 2, p. 119-138, jul./dez. 2014. 
dos procedimentos metodológicos levados a cabo na análise do guião destinado à realização de uma entrevista semiestruturada, enquadrada numa investigação científica. Colocámos, seguidamente, uma questão de partida para a investigação e três objetivos gerais, que passamos a apresentar:

- Questão de partida: Quais são os procedimentos desejados / desejáveis para a utilização da técnica de recolha de dados "inquérito por entrevista" numa investigação científica?

- Objetivos da investigação: (i) Conhecer os procedimentos necessários para a utilização da técnica de recolha de dados "inquérito por entrevista" numa investigação científica; (ii) Produzir uma 'Lista de Verificação / Checklist Avalitiva' conducente à validação de guiões de entrevistas; (iii) Clarificar o papel do investigador na análise de conteúdo do discurso produzido numa entrevista semiestruturada.

\section{FUNDAMENTOS EPISTEMOLÓGICOS DO ESTUDO}

Centrámo-nos no paradigma interpretativista, assumindo que o conhecimento emerge como resultado das interpretações dos investigadores-avaliadores acerca do discurso analítico e reflexivo do investigador-inicial sobre as perceções manifestadas pelos atores (no caso concreto deste estudo, trata-se de atores escolares), inquiridos através de questionário por entrevista semiestruturada.

Para Souza e Prado (2009) o paradigma interpretativista comporta as características que o Quadro1 apresenta.

Quadro 1 - Características do Paradigma Interpretativista

\begin{tabular}{|cc|}
\hline \multicolumn{2}{|c|}{ Paradigma Interpretativista } \\
\hline Teorias & Técnicas \\
\hline Hermenêutica, Etnometodologia e & Realização e Produção de Sentido, \\
Interacionismo Fenomenológico & Jogos de Linguagem e Texto \\
\hline
\end{tabular}

Fonte: Adaptado de Souza \& Prado, 2009.

Encontramos os principais fundamentos teóricos da análise de conteúdo ancorados no pensamento de Adam (2010), Bakhtin (1992), Bardin (2007) e van Dijk (2003). Assim, conscientes de que toda a experiência humana é mediada pela interpretação (SOUZA \& PRADO, 2009) e que toda a interpretação resulta de um processo dialógico entre investigador-interpretante e realidade interpretada que apenas a Comun. \& Inf., Goiânia, GO, v. 17, n. 2, p. 119-138, jul./dez. 2014. 
palavra torna conhecimento (BAKHTIN, 1992), consideramos que toda a investigação qualitativa resulta processo de construção e reconstrução da realidade,

Por meio de um vai-e-vem constante (dialética) entre as interpretações e as reinterpretações sucessivas dos indivíduos (dialogicidade e complexidade) para estudar e analisar em sua totalidade um determinado fato, objeto e ou fenômeno da realidade. (OLIVEIRA, 2011, p. 131)

A consciência de que a realidade chegará ao investigador apenas e sempre de forma mediada, pois o conhecimento alicerçar-se-á sempre na linguagem, é uma das condições sine qua non da investigação, mormente da investigação qualitativa. $\mathrm{O}$ recurso a instrumentos de investigação validados poderá constituir a forma de minimizar a subjetividade do investigador, conferindo ainda fiabilidade e confiabilidade à investigação.

Defendemos que no seio do paradigma interpretativista e da análise qualitativa: a) a credibilidade, a fiabilidade e a confiabilidade da investigação devem ser asseguradas pelo investigador, nomeadamente através do recurso à triangulação de fontes e de instrumentos; b) o rigor e a justeza devem estar subjacentes em todas as fases da investigação, podendo alcançar-se, nomeadamente, através do conhecimento aprofundado, direto epróximo do objeto de estudo (arealidade), da preocupação contínua com o estado da arte e, ainda, através de um constante recentramento nos objetivos investigativos; em sede de análise de conteúdo, a Semântica, "que se dedica às noções de verdade e de valor informativo", segundo Serra (1996, p. 10), e a Pragmática encontram-se associadas (DUCROT, 1984).

\section{MÉTODO}

A recolha e a análise dos dados deste estudo reflexivo de meta-análise que teve por base a análise de conteúdo iniciaram-se com a produção da Matriz Avaliativa que sustentou a análise da Matriz de Categorização que, por sua vez, esteve subjacente à elaboração do Guião da Entrevista, usadas na análise de conteúdo inicial.

As fases e procedimentos metodológicos que levámos a cabo são demonstrados na Figura 1 e seguem o modelo 'clássico' de qualquer procedimento investigativo duma abordagem qualitativa. Sublinhamos, contudo, que a tarefa que nos havíamos proposto se revestia de uma característica intrínseca que convém não esquecer: a de averiguar da

Comun. \& Inf., Goiânia, GO, v. 17, n. 2, p. 119-138, jul./dez. 2014. 
'qualidade' de um produto (uma técnica investigativa), ou seja, a de proceder a uma meta-avaliação.

Figura 1: Fases da investigação.

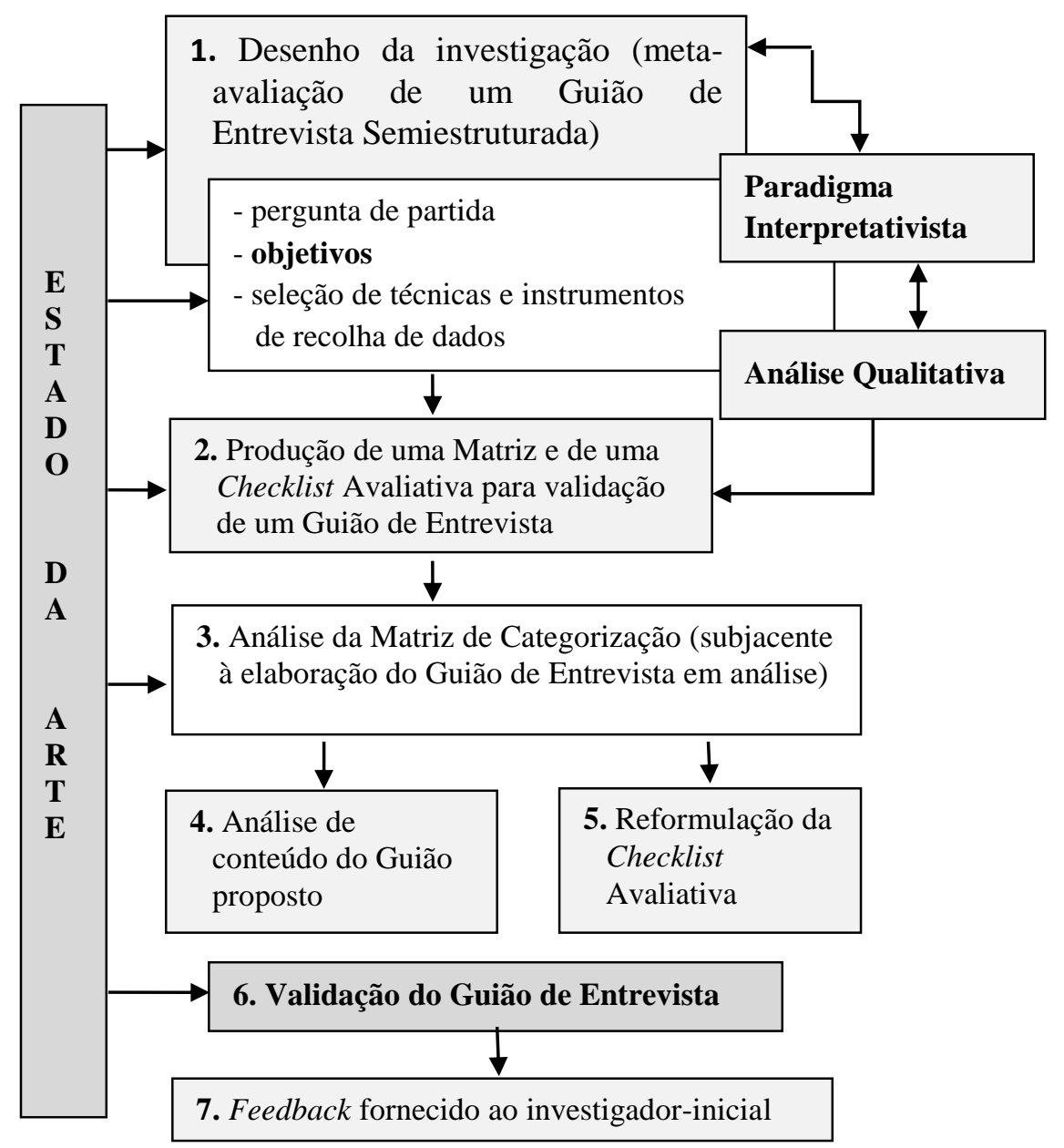

\section{APRESENTAÇÃO E DISCUSSÃO DOS RESULTADOS}

\subsection{A utilização da técnica de recolha de dados "inquérito por entrevista" numa investigação científica}

O inquérito por entrevista é uma técnica de recolha de dados cujo uso se revela fortemente adequado a estudos de âmbito qualitativo, pelo elevado número de informações que permite recolher, sendo, contudo, necessário que o investigador assegure a necessária definição de critérios, de modo a conferir confiabilidade e cientificidade ao seu estudo. As entrevistas permitem ao investigador recolher um talnúmero de informações que conduzem a uma descrição e compreensão profunda da realidade estudada (DUARTE, 2004). Este importante instrumento metodológico largamente utilizado na investigação qualitativa (AFONSO, 2005, CORREIA, 2007),

Comun. \& Inf., Goiânia, GO, v. 17, n. 2, p. 119-138, jul./dez. 2014. 
permite a construção de conhecimento a partir dos constructos internos dos indivíduos inquiridos, manifestados na sua linguagem (ROCHA-PINTO, 2010).

A tarefa investigativa com recurso ao inquérito por entrevista tem início com a definição dos itens constitutivos de um guião orientador da condução da entrevista, uma vez que se trata de realizar uma entrevista semiestruturada. Defendemos que, sempre que num determinado estudo se proceda à inquirição de várias pessoas através de entrevista, o investigador deve recorrer ao mesmo guião orientador, sendo esse um dos fatores que conferirão rigor e fiabilidade a essa técnica de recolha de dados. $\mathrm{O}$ guião da entrevista deve, por conseguinte, ser entendido como um roteiro ou guia orientador da condução da entrevista, ou seja, as perguntas devem ir sendo (re)orientadas durante o processo de interação entrevistador/entrevistado.

$\mathrm{Na}$ fase inicial da etapa investigativa, impõe-se, pois, que se proceda à produção do guião da(s) entrevista(s), o qual deve ser estruturado em blocos temáticos, tendo em conta os objetivos gerais da investigação. A partir desses objetivos gerais, devem ser estabelecidos objetivos específicos e, numa estratégia de antecipação de uma eventual dificuldade de compreensão da metalinguagem utilizada pelo investigador, por parte do(s) inquirido(s), deve o investigador incluir nesse guião um conjunto de questões subsidiárias na medida em que a entrevista é uma técnica investigativa de cariz dialogístico ao nível da interação verbal em copresença.

Não parece irrelevante a inclusão de um quarto item a inserir no guião da entrevista: o espaço físico no qual o investigador/entrevistador possa registar algumas informações contextuais, que recolha no decurso da entrevista, ou para observações. De facto, na aplicação de uma entrevista semiestruturada é relevante o papel do investigador, no sentido em que a sua sensibilidade para produzir conhecimento a partir de indícios diversos (linguísticos e paralinguísticos, como as entoações e as pausas, as posturas corporais ou as expressões faciais, a velocidade discursiva, entre outros) constitui um fator a não desconsiderar.

A etapa metodológica seguinte consiste na validação do guião da entrevista, por parte de algum(ns) perito(s), reconhecido(s) no meio académico. Defendemos que o guião deve ser acompanhado de uma breve contextualização da investigação que inclua a questão de partida e os objetivos da investigação, por forma a permitir ao(s) investigador(es) externo(s) à investigação - que aqui assumem o papel de avaliadores a tarefa de validação desse instrumento de recolha de dados. Após a receção do

Comun. \& Inf., Goiânia, GO, v. 17, n. 2, p. 119-138, jul./dez. 2014. 
feedbackapreciativo, deve proceder-se à inclusão das propostas de melhoria do instrumento, concluindo-se dessa forma o processo de validação prévia desse guião de entrevista.

Segue a etapa metodológica de testagem do guião de entrevista ou entrevista-modelo, aplicada a um ator não incluído no estudo. Os procedimentos a empreender devem coincidir com os observados posteriormente, aquando da realização das entrevistas que servirão de base ao estudo, nomeadamente, a transcrição da entrevista realizada e o envio para submissão de concordância por parte do inquirido.

Acreditamos que esta etapa da investigação poderá permitir a verificação da adequação do guião de entrevista, sendo mesmo de prever a sua eventual reformulação, ainda que pontual. Consideramos ser fundamental e de grande pertinência esta fase da investigação, na qual podem ganhar relevância alguns eventuais problemas do guião (demasiado extenso, redundância do questionamento, desajustamento das questões relativamente aos objetivos propostos) ou a chamada de atenção para alguns aspetos práticos que poderão afetar e dificultar a investigação (interrupções que ocorreram durante a gravação da entrevista, aos desvios dos tópicos e das questões abordadas quando o entrevistado desloca o seu discurso para algum tópico que lhe interessa bem mais do que aqueles que o entrevistador pretende abordar - entre outros aspetos inesperados), que essa primeira interação entre entrevistador e entrevistado pode desvendar.

Para uma mais fiel e fidedigna recolha de informações, a entrevista deve ser áudio-gravada, processo que facilita a concentração do entrevistador no discurso do seu interlocutor, impedindo a sua dispersão com a tomada de notas.

A fase seguinte deverá ser a da transcrição da entrevista. Günther (2006, p. 204) considera esta a terceira de quatro fases: “a) delineamento, b) coleta de dados, c) transcrição e d) preparação dos mesmos para sua análise específica", sublinhando que

Existem muitas combinações entre os diferentes delineamentos, maneiras de coletar, transcrever e analisar os dados. Frequentemente, manuais da pesquisaqualitativa apresentam coleta e análise de dados interligados (por exemplo, Camic, Rhodes \& Yardley, 2003; Denzin \& Lincoln, 1994). Mesmo que se considere tal junção interessante, já que mostra a integração entre coleta e análise, tal procedimento tende a ocultar as demais possibilidades de combinar elementos destas técnicas de pesquisa. (GÜNTHER, 2006, p. 204)

Comun. \& Inf., Goiânia, GO, v. 17, n. 2, p. 119-138, jul./dez. 2014. 
Também nesta etapa se revela de extrema importância o papel (e a experiência) do investigador, uma vez que a sua sensibilidade para produzir conhecimento a partir de indícios diversos (linguísticos e paralinguísticos, como as entoações e as pausas, as posturas corporais ou as expressões faciais, a velocidade discursiva, entre outros) pode constituir um fator a não desconsiderar. Trata-se, pois, de proceder a uma recriação de um contexto em que o uso da palavra (o discurso) oral é fixado na escrita, passando pelo crivo do olhar interpretativo do investigador-redator, o qual, por sua vez, também ele é contextualizado e fruto de uma determinada vivência e visão do mundo. É deste entrelaçar de visões do mundo e da realidade que nasce o discurso escrito: o investigador-escrevente reproduz aquilo que perceciona como sendo a perceção dos factos do seu inquirido-falante.

Daí que a etapa seguinte se revele de enorme pertinência. Assim, após a transcrição, deverá proceder-se à validação do conteúdo das entrevistas, por parte do entrevistado. Trata-se não só de garantir a validação do(s) discurso(s) por parte do(s) sujeito(s) da enunciação, mas também no assegurar da dialogicidade processual que a técnica da entrevista pressupõe e impõe.

Finalmente, segue-se a fase de análise de conteúdo da entrevista, que consideramos não poder ser uma leitura interpretativa neutra. De facto, a análise de conteúdo linguístico deve ser entendida pelo investigador como uma interpretação pessoal, por parte do pesquisador, com relação à perceção que tem dos dados (MORAES, 1999) e que a análise discursiva permite coconstruir. Ou seja, na análise de conteúdo e na produção de sentido o investigador não pode deixar de analisar os dados usando também o seu próprio ponto de vista (PONTE, 2008).

A coconstrução de conhecimento resulta da dialogicidade processual, presente em toda a comunicação, quer esta se efetue presencialmente ou à distância, em copresença ou diferidamente (BAKTHIN, 1992; OLIVEIRA, 2014), uma vez que não existem leituras neutras (KINCHELOE, 1997). E, embora tratando-se de produzir conhecimento científico, o discurso de todo o investigador é sempre marcado, quer do ponto de vista conceptual, quer do ponto de vista contextual. Efetivamente, não são os dados que 'falam' por si, é a voz do investigador que se faz 'ouvir/ler', na lógica da sua narrativa.

Comun. \& Inf., Goiânia, GO, v. 17, n. 2, p. 119-138, jul./dez. 2014. 
A riqueza desse discurso será, cremos, tanto maior quanto mais vasto for o manancial de 'ferramentas' cognitivas e de 'instrumentos' comunicativos de que ele faça uso.

De facto, a investigação qualitativa parece-nos o campo ideal para retratar em profundidade uma qualquer realidade objetiva, fazendo uso da indução, da descrição, das inferências, dos subentendidos e dos implícitos conversacionais (ADAM, 1990; BOGDAN \& BIKLEN, 1994; DUCROT, 1984; VAN DIJK, 1983). Convém ter sempre presente que "uma pesquisa é sempre, de alguma forma, um relato de longa viagem empreendida por um sujeito cujo olhar vasculha lugares muitas vezes já visitados" (DUARTE, 2002, p. 140). Assim, todo o sujeito-investigador deve ousar olhar de um modo original e diferente - porém consciente dessa originalidade e diferença - para os dados emanados de uma determinada realidade, a partir da sua experiência pessoal, com o propósito de produzir conhecimento sobre o objeto do estudo.

\subsection{A validação de guiões de entrevistas (Lista de Verificação / Checklist Avaliativa)}

A meta-avaliação encontra-se legitimada, cremos, pela necessidade de os avaliadores melhorarem o seu trabalho, fundamentados em novos conceitos $\mathrm{e}$ instrumentos. Foi, pois, com o objetivo de facilitar a tarefa de 'validação de guiões de entrevista', por parte de investigadores externos à investigação primária, (o processo que o investigador-autor do guião de entrevista em análise levará a cabo e não a avaliação que lavámos a cabo e aqui explanamos), que procedemos à autometa-análise dos nossos procedimentos.

A meta-avaliação é um meio para assegurar e comprovar a qualidade das avaliações que, em educação, apesar de ser definida de diversas maneiras, remete na maioria das vezes para o valor e o mérito do objeto educacional (DAVOK, 2006; STUFFLEBEAM, 2001). Assim, sendo que o objetivo primordial deste trabalho consiste em produzir e apresentar um instrumento meta-avaliativo, sob a forma de 'lista de verificação' ou checklist avaliativa, parece-nos importante começarmos por apresentar dois aspetos essenciais: em primeiro lugar, defendemos que a aplicação de qualquer instrumento estandardizado exige qualificação e juízo profissional, análise aprofundada e reflexão crítica, por parte do investigador-avaliador, para se poder, em cada caso prático, avaliar a qualidade do guião de entrevista. Em segundo lugar, ela

Comun. \& Inf., Goiânia, GO, v. 17, n. 2, p. 119-138, jul./dez. 2014. 
pode constituir-se como um recurso formativo em avaliação e na qualificação quer de avaliadores, quer de investigadores, tal como preconiza Rodrigues (2009) a propósito dos quatro grandes atributos de uma avaliação de qualidade ${ }^{5}$ : adequação ética, utilidade, exequibilidade e rigor / exatidão.

Validar um guião de entrevista consiste, pois, num ato de atribuição de 'qualidade' a esse instrumento investigativo. O conceito de 'qualidade' surge geralmente associado à eficiência nos processos, à eficácia nos resultados e ao conceito de accountability (DIAS SOBRINHO, 2008), podendo este relacionar-se com outros dois conceitos (DIAS SOBRINHO, 2003): o conceito de responsabilidade/responsabilização e o conceito de prestação de contas aos stakeholders, sem que o avaliador possa perder de vista todas as dimensões intrínsecas à atribuição dessa 'qualidade': a dimensão pedagógica, a dimensão científica, a dimensão técnica e a dimensão ética (DIAS SOBRINHO, 2008).

Assim, assumindo que as três principais funções de um processo avaliador são o aperfeiçoamento, a recapitulação e a exemplificação (RODRIGUES, 2009), apresentamos na Tabela I a 'Lista de Verificação / Checklist Avaliativa', que surgiu como resultado dessas (três) tarefas que, resumidamente e em termos genéricos, a comunidade científica reconhece como 'processo de validação' de um guião de entrevista.

Quadro 2 - Matriz Avaliativa de um Guião de Entrevista Semiestruturada

\begin{tabular}{|c|c|c|}
\hline \multicolumn{3}{|c|}{ Indicadores } \\
\hline \multicolumn{3}{|c|}{ 1.O Guião está dividido em Blocos Temáticos. } \\
\hline \multicolumn{3}{|c|}{ 2. O Guião integra os Objetivos Gerais da investigação. } \\
\hline \multicolumn{3}{|c|}{ 3. Os Blocos Temáticos estão diretamente relacionados com os Objetivos Gerais da investigação. } \\
\hline \multicolumn{3}{|c|}{ 4. Traçam-se Objetivos Específicos, a partir dos Objetivos Gerais da investigação. } \\
\hline \multicolumn{3}{|c|}{ 5. O número de perguntas dos diferentes Blocos Temáticos é equilibrado. } \\
\hline \multicolumn{3}{|c|}{$\begin{array}{l}\text { 6. O Guião inclui um campo para Questões subsidiárias OU para inclusão de Especificidades / } \\
\text { Observações (antecipando uma eventual dificuldade na compreensão de vocabulário técnico, } \\
\text { permitem a simplificação das questões,...). }\end{array}$} \\
\hline \multirow{2}{*}{\multicolumn{3}{|c|}{$\begin{array}{l}\text { 7. O design do Guião permite que este seja facilmente aplicado por qualquer pessoa. } \\
\text { 8. A estrutura do Guião permite que ele seja fácil e logicamente transformado numa Matriz de } \\
\text { Categorização conducente à análise de conteúdo da(s) entrevista(s). }\end{array}$}} \\
\hline & & \\
\hline \multirow{7}{*}{$\begin{array}{l}\text { 9. O texto apresenta rigor } \\
\text { formal (capaz de conferir } \\
\text { unicidade, coesão e } \\
\text { coerência textuais) devido } \\
\text { à uniformização no uso } \\
\text { de: }\end{array}$} & 9.1.tipo e tamanho de letra; & \\
\hline & 9.2. justificação do texto; & \\
\hline & 9.3. símbolos e sinais auxiliares da escrita; & \\
\hline & 9.4. alíneas e subalíneas; & \\
\hline & $\begin{array}{l}\text { 9.5. pontuação (uso de ponto de interrogaçãao nas } \\
\text { questões e de ponto final nas afirmaçôes); }\end{array}$ & \\
\hline & 9.6. siglas e acrónimos; & \\
\hline & 9.7. maiúsculas/minúsculas; & \\
\hline
\end{tabular}

${ }^{5}$ Apresentados numa pragmática recensão sobre o Joint Committee on Standards for Educational Evaluation.

Comun. \& Inf., Goiânia, GO, v. 17, n. 2, p. 119-138, jul./dez. 2014. 
10. Existe uma formulação correta de "Objetivos" e "Questões".

11. Há inexistência de redundâncias nas diversas questões.

12. Verifica-se a inexistência de contradições nas diversas questões.

13. Existe clareza discursiva, na exposição de intenções e na formulação de questões.

14. O discurso é adequado à situação comunicativa concreta, incluindo ao(s) inquirido(s).

A meta-avaliação capaz de resultar na validação de um guião de entrevista consiste, pois, num procedimento realizado após a produção desse guião, avaliando de uma forma circular todas as suas componentes, bem como a relação existente entre elas, que se aproxima, do nosso ponto de vista, da conceção de 'avaliação formativa' exposta por Fernandes (FERNANDES, 2007): trata-se de fornecer ao investigador-autor do guião um feedback indicativo da 'fiabilidade' e a 'confiabilidade' do instrumento de pesquisa que, por sua vez, conferirá essas 'fiabilidade' e 'confiabilidade' à sua investigação, por via da 'fiabilidade' e 'confiabilidade' dos dados que a entrevista permitir apurar. Assim, será a circularidade processual que conferirá validade à análise de conteúdo do guião de entrevista.

Importa, portanto, centrarmos a nossa atenção nas questões da análise de conteúdo. Diferentes autores, oriundos de áreas/disciplinas científicas várias (BARDIN, 2007; FARIAS, 2000; KEATING, 2008; MORAES, 1999; MORGAN, 2010; MAYTING, 2000; NIKANDER, 2006; VAN DIJK, 2003) defendem que a análise de conteúdo deve estar em permanente revisão, uma vez que a análise dos dados deve processar-se de forma cíclica e circular, e não de forma sequencial e linear, pois os dados não falam por si: necessitam do olhar e da atenção do investigador para deles extrair significado, em confluência com os objetivos da investigação. Importa ainda sublinhar que, em sede de análise de conteúdo, a Semântica, dedicada às noções de verdade e de valor informativo (SERRA, 1996), e a Pragmática encontram-se associadas (DUCROT, 1984), pelo que o procedimento avaliativo do guião de entrevista deve ser, como qualquer outra análise de conteúdo, contextualizada.

\subsection{O papel do investigador na análise de conteúdo do discurso produzido numa entrevista semiestruturada}

O inquérito por entrevista é uma técnica de recolha de dados que, a nosso ver, se revela eficaz em estudos que tenhamcomo intenção a análise em profundidade da realidade, ou melhor, quando se trate de compreender e interpretar a realidade a partir da representação que dela evidenciam os diversos atores organizacionais participantes (BELL, 2005; BOGDAN \& BIKLEN, 1994; COUTINHO \& CHAVES, 2002; FLICK,

Comun. \& Inf., Goiânia, GO, v. 17, n. 2, p. 119-138, jul./dez. 2014. 
2005; VIEIRA, 1999). Fernandes (2008) defende que no paradigma investigativo qualitativo o investigador é o instrumento de recolha de dados por excelência, uma vez que da sua sensibilidade, integridade e conhecimento dependem a fiabilidade e a validade da investigação.

Adam (1990) esclarece que na análise de conteúdo de um texto ou análise do discurso o investigador tem por objetivo não apenas descrever os discursos através dos meios linguísticos e paralinguísticos mobilizados, mas também pretende construir uma compreensão da própria produção de sentido, ou seja, das operações necessárias à realização do sentido produzido. Outro dos pressupostos teóricos nos quais fundamos a nossa análise é a tese de van Dijk e Kintsch (1983), segundo o qual um texto não pode ser compreendido meramente pela interpretação do seu conteúdo frásico ou estrutura de superfície, sendo antes necessário proceder à sua integração num tipo textual específico e recorrer a informações contextuais que permitam a análise discursiva profunda. Para Ducrot (1984) a palavra atualiza-se no discurso e este ganha sentido no contexto em que é produzido.

Durante a análise de conteúdo dos dados recolhidos através do inquérito por entrevista, o investigador deve ter consciência do seu papel na compreensão e a (re)construção dos significados produzidos pelos atores ouvidos em entrevista, e que os mesmos exteriorizaram no seu discurso. Neste quadro, definimos texto como o produto verbal de um ato comunicativo, e discurso como o processo de produção/construção desse texto, socialmente condicionado, seguindo as definições de Ducrot (1984), Adam (2010) e van Dijk (1983).

A perceção do conteúdo e, de modo especial, as inferências que o investigador produzir ao longo da sua interpretação e análise discursiva, devem ter sempre subjacentes os objetivos propostos para a investigação, bem como a preocupação constante de conferir credibilidade e fiabilidade à análise de conteúdo. Yin (2003) chama a atenção para o facto de, no quadro de uma metodologia qualitativa a validade do método poder conseguir-se através da comparação de dados e da evidenciação quer de semelhanças, quer de contrastes.

Diversos autores (ANTAKI, BILLIG, EDWRDS \& POTTER, 2003; NIKANDER, 2006; PAGE, 1997) chamam a atenção para o facto de a análise discursiva ser um terreno complexo, já que o contexto de produção do discurso precisa de ser reconstruído em sede de análise do seu conteúdo,embora os dados estejam

Comun. \& Inf., Goiânia, GO, v. 17, n. 2, p. 119-138, jul./dez. 2014. 
expressos diretamente no texto. Duas ordens de razões subjazem a esta necessidade: por um lado, a narrativa do investigador deve facilitar ao leitor a compreensão do que se tenciona demonstrar (e recordamos, a propósito, duas das funções da linguagem enunciadas por Meyer (198): a comunicação indicativa e referencial de factos e a expressão da subjetividade); por outro lado, trata-se de conferir fiabilidade aos dados que a investigação permite recolher e à sua análise. Não nos esqueçamos que em sede de análise de dados qualitativos, em geral, e de análise de conteúdo do discurso de outros em particular (como é o caso de toda a investigação apoiada na técnica de inquérito por entrevista), a linguagem é utilizada pelo sujeito-investigador para expressar o seu entendimento/interpretação da linguagem utilizada por outros (o/os sujeito(s)/produtores do texto interpretado) para expressarem o seu entendimento/interpretação não só da realidade (o referente da linguagem, as temáticas abordadas no decurso das entrevistas), mas também da sua própria linguagem, ou seja, das questões formuladas durante a própria entrevista (NIKANDER, 2006).

Sendo que o conhecimento dos inquiridos é sempre pessoal e parcial e que, para além do mais, os inquiridos podem responder de acordo com o que se espera deles, de uma forma social ou politicamente correta, cremos que se justifica inequivocamente, do ponto de vista da validade investigativa, a criação e aplicação de um referencial de critérios que permitam a categorização das unidades de análise, com vista a salvaguardar o risco implícito em qualquer interpretação linguística, como se apresenta no Quadro 3, a partir da investigação bibliográfica levada a cabo (KINTSCH \& VAN DIJK, 1983; YIN, 2003; MORAES 1999; MAYRING, 2000; NIKANDER, 2006; VENESSON, 2008; BOADOU, 2011).

\begin{tabular}{|l|l|}
\multicolumn{1}{c}{ Quadro3 - Referencial de categorização } \\
\hline \multirow{4}{*}{ CRITÉRIOS } & \multicolumn{1}{c|}{ SUBCRITÉRIOS } \\
\hline \multirow{4}{*}{ C1- pertinência } & C1.1. adequação \\
\cline { 2 - 2 } & C1.2. peculiaridade /especificidade \\
\cline { 2 - 2 } & C1.3. coesão \\
\cline { 2 - 2 } & C1.4. homogeneidade \\
\hline \multirow{2}{*}{ C2- recorrência } & C2.1. exclusividade \\
\cline { 2 - 2 } & C2.2. inclusividade \\
\hline \multirow{2}{*}{ C3- consistência } & C3.1. objetividade \\
\cline { 2 - 2 } & C3.2. coerência \\
\hline
\end{tabular}

Esse referencial de critérios para seleção das unidades de análise, constitui-se como um instrumento válido aquando do preenchimento das grelhas de análise.

Comun. \& Inf., Goiânia, GO, v. 17, n. 2, p. 119-138, jul./dez. 2014. 
A leitura atenta das entrevistas possibilitará a identificação dos dados, donde resultará o preenchimento das diferentes grelhas e subgrelhas de categoriais, onde o investigador fará o registo da informação-reveladora (VENTURA, 2006). Importa que o investigador se assegure da captação das principais linhas de conteúdo do enunciado em análise, bem como da evidenciação dos segmentos críticos relevantes constantes do discurso. Poderá, depois, passar a uma análise criteriosa do conteúdo: procedendo a comparações e a contrastes constantes, marcando as presenças, as ausências e as recorrências de ocorrências linguísticas.

Assim, propomos que a análise de conteúdo dos dados das entrevistas se processe de acordo com as etapas apresentadas na Figura 2.

Figura 2 - Etapas da análise de conteúdo.

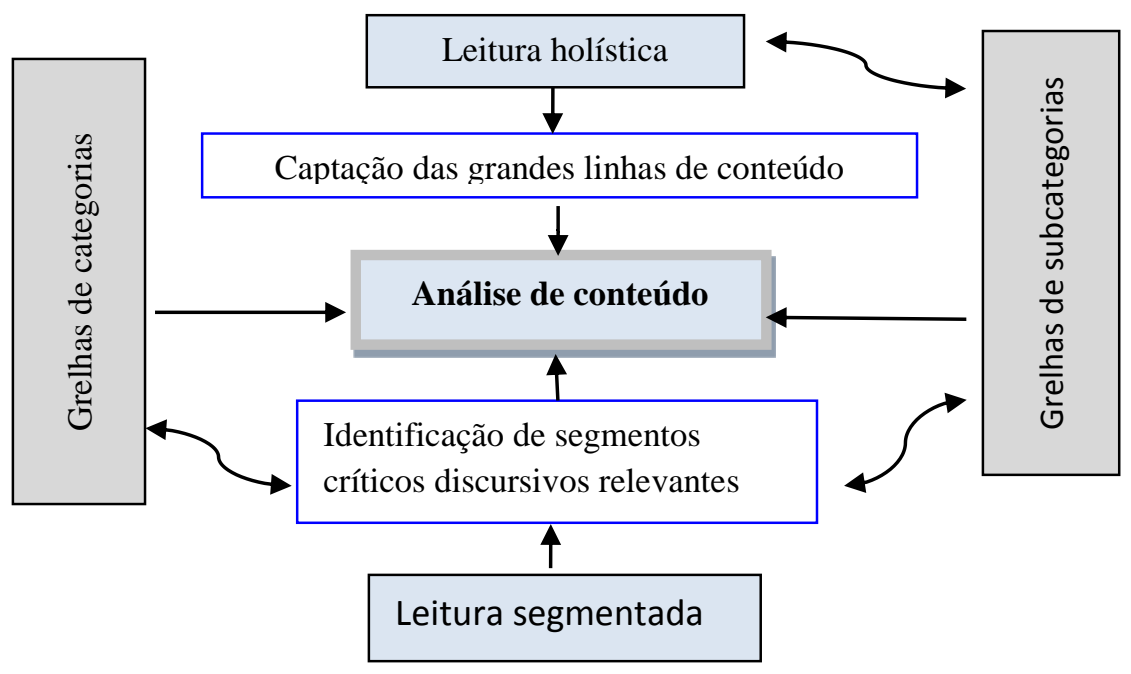

O papel do investigador, numa abordagem qualitativa, é, pois, centralmente o de um interpretante do discurso de outros para, através do seu próprio discurso, coconstruir sentidos e produzir conhecimento acerca da realidade que investiga. A sua análise do conteúdo discursivo não pode ser apenas linear, antes devendo constituir-se enquanto leitura revisitada, tendo em conta os objetivos da investigação.

Desta forma, se numa primeira leitura das entrevistas poderão ser captadas as grandes linhas de sentido do discurso, apenas uma segunda leitura, segmentada por blocos de questões, permitirá novos olhares e novos significados e, eventualmente, a emergência de novas subcategorias não pensadas à partida: o discurso é fluido, não é rígido, pelo que o labor investigativo de cariz qualitativo não se esgota facilmente,

Comun. \& Inf., Goiânia, GO, v. 17, n. 2, p. 119-138, jul./dez. 2014. 
sendo "a escrita [e a reescrita] o espelho da exigência, da sistematicidade e da criatividade" (AMADO, 2014, p. 56) do investigador.

As três operações analíticas (QUIVY \& CAMPENHOUDT, 2008) a que o investigador deve proceder, com vista à apresentação e discussão dos dados, consistirão (1) na preparação dos dados (através da sua descrição e agregação), (2) na análise comparativa entre os dados encontrados e (3) na interpretação dos dados, à luz de bibliografia de referência. A produção de textos interpretativos, fundamentados na literatura, serve o objetivo maior de melhorar a compreensão da realidade em estudo, nesse dialogismo polifónico que constitui a apresentação de uma análise de conteúdo, no decurso de uma investigação.

\section{CONSIDERAÇÕES FINAIS}

A utilização da técnica investigativa do inquérito por entrevista é uma importante ferramenta no âmbito das ciências da educação e, em geral, das ciências sociais e humanas, permitindo alcançar um conhecimento profundo do objeto de estudo, na mediada em que permite que o investigador passe da palavra do entrevistado à (re)construção de sentidos.

A entrevista é uma das principais técnicas de recolha de dados de uma abordagem qualitativa (WOLCOTT, 1994). O recurso ao inquérito por entrevista tem início com a definição dos itens constitutivos de um guião orientador da condução da entrevista, caso o investigador opte por realizar uma entrevista semiestruturada, passando ainda pelas etapas subsequentes de (i) validação do guião (validação externa por peritos), (ii) aplicação da entrevista-modelo (para validação interna, por parte do próprio investigador) e (iii) eventual reformulação do guião, (iv) realização, (v) transcrição e (vi) validação da entrevista por parte do inquirido e, finalmente (vii) a análise de conteúdo da entrevista.

Validar um guião de entrevista consiste num ato de atribuição de 'qualidade' a esse instrumento investigativo. A meta-avaliação de um guião de entrevista semiestruturada - tarefa acometida ao investigador externo/perito/avaliador - pode revelar-se de extrema pertinência e validade, uma vez que da validação do guião dependerá, em última instância, o resultado mais ou menos conseguido da tarefa investigativa. Assim, o objetivo primordial deste trabalho consistiu na produção e na apresentação de um instrumento meta-avaliativo, sob a forma de 'lista de verificação'

Comun. \& Inf., Goiânia, GO, v. 17, n. 2, p. 119-138, jul./dez. 2014. 
ou checklist avaliativa, que integra catorze indicadores capazes de permitirem a atribuição de mais ou menos qualidade ao guião de entrevista em análise.

Porém, importa que todos os investigadores envolvidos no processo perfilhem do mesmo ponto de vista, não esquecendo que, numa investigação centrada no paradigma interpretativista e em análise de dados qualitativa, a análise de conteúdo deve estar em permanente revisão, devendo processar-se de forma cíclica e circular. Os dados não falam por si, necessitam do olhar e da atenção do investigador para deles extrair significados, em confluência com os objetivos da investigação.

\section{REFERÊNCIAS}

ADAM, J. M. Élements de linguistique textuelle. Liège: Mardaga, 1990.

ADAM, J. M. A análise textual dos discursos: entre gramáticas de texto e análise do discurso. Lyon: Universidade de Lyon II, 2010.

AFONSO, Natércio. Investigação naturalista em educação. Porto: Edições Asa, 2005.

AMADO, J. A formação em investigação qualitative: notas para a construção de um programa. In: COSTA, A. P., SOUZA, F. N.; SOUZA, D. N. Investigação qualitaiva: inovação, dilemas e desafios. Bustelo: Ludomedia, 2014. p. 39-67.

ANTAKI, Charles. Discourse analysis means doing analysis: a critique of six analytic shortcomings. Discourse Analysis Online, Loughborough, v. 1, n. 1, ago. 2003. Disponível em: <http://www.shu.ac.uk/daol/previous/v1/n1/index.htm>. Acesso em: 21 jun. 2014.

BAKHTIN, M. M. Estética da criação verbal. São Paulo: Martins Fontes, 1992.

BARDIN, Laurence. Análise de conteúdo. 3 ed. Lisboa: Edições 70, 2007.

BELL, J. Doing your research project: a guide for the first-time researchers in education, helth and social science, 4. ed. Glasgow: Bell y Brain, 2005.

BOADUO, N. A. P. Systematic analysis and interpretation of collected data for a research study: a practical methodological framework for writing research report. Educational Research and Review, v.6, n. 2, p. 140-146, 2011.

BOGDAN, R.; BIKLEN, S. Investigação qualitativa em educação. Porto: Porto Editora, 1994.

COUTINHO, C.; CHAVES, J. H. O estudo de caso na investigação em tecnologia educativa em Portugal. Revista Portuguesa de Educação, v. 1, n. 15, p. 221-243, 2002.

DAVOK, Delsi Fries. Modelo de meta-avaliação de processos de avaliação da qualidade de cursos de graduação. 2006. 272 f. Tese (Doutorado) - Curso de Engenharia de Produção, Programa de Pós-graduação em Engenharia de Produção, Universidade Federal de Santa Catarina, Santa Catarina, 2006.

DIAS SOBRINHO, José. Avaliação educativa: produção de sentidos com valor de Formação. Avaliação: Revista da Avaliação da Educação Superior, v. 13, n. 1, p.193-208, mar. 2008.

Comun. \& Inf., Goiânia, GO, v. 17, n. 2, p. 119-138, jul./dez. 2014. 
DIAS SOBRINHO, José. Avaliação: políticas educacionais e reformas da educação superior. São Paulo: Cortez Editora, 2003.

DUARTE, Rosália. Entrevistas em pesquisas qualitativas. Educar: em revista, Curitiba, v. [s.i.], n. 24, p.213-225, [s.i.] 2004.

DUARTE, Rosália. Pesquisa qualitativa: reflexões sobre o trabalho de campo. Cadernos de Pesquisa, Maranhão, v. [s.i.], n. 115, p.139-154, mar. 2002. Disponível em: <http://www.scielo.br/pdf/cp/n115/a05n115.pdf >. Acesso em: 9 jun. 2012.

DUCROT, O. Enunciação. Enciclopédia Einaudi, n. 2, Lisboa: Imprensa Nacional; Casa da Moeda, 1984. p.368-393.

ELLIOT, L. G. Meta-avaliação: das abordagens às possibilidades de aplicação. Ensaio: Avaliação e Políticas Públicas em Educação, v.19, n.73, p. 941-964, 2011.

FARIAS, W. S. Compreensão e resumo de textos: alguns aspetos teóricos e experimentais. Revista de Letras, v. 1/2, n. 22, p.103-110, jan./dez. 2000.

FERNANDES, Domingues. Notas sobre os paradigmas de investigação em educação. Noesis, v. [s.i.], n.18, p.64-66, 1991.

FERNANDES, Domingues. Avaliação das aprendizagens: desafios às teorias, práticas e políticas. Lisboa: Texto Editores, 2008.

FLICK, U. Métodos qualitativos na investigação científica, 1. ed. Lisboa: Monitor, 2005.

KEATING,M. Culture and social silence. In DELLA PORTA,D.; KEATING, M. (Eds.). Approaches and methodologies in the social sciences: a pluralist perspective, Cambridge: University Press, 2008. p. 99-117

KINCHELOE, J. Pesquisa-ação, reforma educacinal e pensamento do professor. In:

KINCHELOE, J. A formação do professor como compromisso político: mapeando o pósmoderno. Porto Alegre: Arte Médicas, 1997. p.179-197.

KINTSCH, W.; VAN DIJK, T. A. Strategies of discourse comprehension. San Diego, California: Academic Press, 1983.

MAYRING, Philipp. Qualitative Content Analysis. Forum: Qualitative Social Research Sozialforschung, Berlin, v. 1, n. 2, p. [s.i.], jun. 2000.

MORAES, R. Análise de conteúdo. Revista Educação, Porto Alegre, v. 22, n. 37, p.7-32. 1999.

MORGAN, Angela. Discourse Analysis: An Overview for the Neophyte Researcher. Journal Of Health And Social Care Improvement, Wolverhampton, v. [s.i.], n. [s.i.], p. 1-7, mai. 2010.

NIKANDER, Pirjo. Constructionism and discourse analysis. In: HOLSTEIN, James A.; GUBRIUM, Jaber F. Handbook of Constructionist Research. New York: Guilford Publitions, 2008. Cap. 21. p. 413-428.

OLIVEIRA, Inês Bernardo. Contributos do Plano da Matemática II para o desenvolvimento profissional dos professores. 2011. 280 f. Dissertação (Mestrado) - Curso de Ciências da Educação, Instituto de Educação, Universidade do Minho, Braga, 2011.

Comun. \& Inf., Goiânia, GO, v. 17, n. 2, p. 119-138, jul./dez. 2014. 
OLIVEIRA, M. M. Círculo hermenêutico-dialético como carro-chefe da metodologia interativa e ferramenta para sequência didática. In: COSTA, Antônio Pedro et al. Investigação qualitativa: inovação, dilemas e desafios. Bustelo: Ludomedia, 2014. Cap. 1.

PAGE, R. N. Teaching about validity. International journal of qualitative studies in education, v. 10, n. 2, p.145-155. 1997.

PONTE, João Pedro. Investigar a nossa própria prática: uma estratégia de formação e de construção do conhecimento profissional. PNA: Revista de Investigación en Didáctica de la Matemática, v.4, n.2, p.153-180. 2008.

QUIVY, R.; VAN CAMPENHOUDT, L. Manual de investigação em ciências sociais. Lisboa: Gradiva, 2008.

ROCHA-PINTO, Sandra Regina; FREITAS, Angilberto Sabino; MAISONNAVE, Paulo Roberto. Métodos interpretativistas em administração: implicações para pesquisadores. Revista de Administração Faces Journal, Belo Horizonte, v. 9, n. 1, p.115-127, 2010.

RODRIGUES, P. Recensão das obras The program evaluation standards; The student evalution standards \& The personnel evaluation standards, do Joint Committee on Standards for Educational Evaluation [1994, 2003, 2009]. Sísifo: Revista de Ciências da Educação, n.9, p.115-118, 2009.

SERRA, Paulo. Retórica e Argumentação. 1995. Disponível em:

<http://www.bocc.ubi.pt/pag/jpserra_retorica.pdf〉. Acesso em: 11 jan. 2013.

SOUZA, Sofia; PRADO, Vaner Jose do. Imagens Da Escola Como Organização: Uma Análise Comparativa Entre o Modelo Burocrático e a Anarquia Organizada através de Metaforas. In: XXXIII ENCONTRO DA ANPAD, 13., 2009, São Paulo, Sp. Anais... . São Paulo, Sp: [s.i.], 2009. p. $1-15$.

STUFFLEBEAM, Daniel. The metaevaluation imperative. American Journal of Evaluation, Thousand Oaks, v.2, n. 22, p. 183-209, 2001.

VAN DIJK, T. A. Ideología y discurso: una introducción multidisciplinaria. Barcelona: Ariel, 2003.

VAN DIJK, T. A; KINTSCH,W. Strategics in discourse comprehension. New York, N.Y.: Academic Press, 1983.

VENESSON, P. Case studies and process tracing: theories and practices. In: DELLA PORTA, D.; KEATING, M. (Eds.). Approaches and methodologies in the social sciences: a pluralist perspective. Cambridge: University Press, 2008. p. 23-23.

SILVA, José Alexandre da Rocha Ventura. Avaliação e inspecção das escolas: estudo de impacte do programa da avaliação integrada. 2006. 968 f. Tese (Doutorado) - Curso de Ciências da Educação, Ciências da Educação, Universidade de Aveiro, Aveiro, 2006.

VIEIRA, Cristina Maria Coimbra. Credibilidade da investigação científica de natureza qualitativa: questões relativas à sua fidelidade e validade. Revista Portuguesa de Pedagogia, Coimbra, v. 33, n. 2, p. [s.i.], 1999.

Comun. \& Inf., Goiânia, GO, v. 17, n. 2, p. 119-138, jul./dez. 2014. 
WOLCOTT, H. F. Transforming qualitative data: description, analysis, interpretation. Thousand Oaks, CA: Sage, 1994.

YIN,K. R. Case study research: design and methods. 3. ed. Thousand Oaks, CA: SAGE Publications, 2003.

Recebido em: 05/09/2014

Aceito em: 27/09/2014

Publicado em: 10/12/2014 